\title{
Educação para paz: um caminhar no pensamento complexo através de cinco pedagogias integradas e complementares
}

Nei Alberto Salles Filho *

\section{Resumo}

Este artigo apresenta os elementos centrais da tese intitulada "Cultura de Paz e Educação para a Paz: olhares a partir da Teoria da Complexidade de Edgar Morin", defendida no Programa de Pós-Graduação em Educação - Mestrado e Doutorado, da Universidade Estadual de Ponta Grossa, Paraná. A tese, de caráter teórico-reflexivo, que tem como objeto de estudo a Educação para a Paz à luz do pensamento complexo, propõe que os processos relacionados às violências e convivências escolares, ganham maior sentido se pensados na integração entre cinco dimensões fundamentais, definidas como as "cinco pedagogias da paz": Pedagogia dos Valores Humanos, Pedagogia dos Direitos Humanos, Pedagogia da Conflitologia, Pedagogia da Ecoformação e Pedagogia das Vivências/Convivências. No decorrer do artigo, argumentamos sobre tais relações. Com a tese em questão, pretende-se avançar na construção da Educação para a Paz como campo de conhecimento e pesquisa no Brasil.

Palavras-chave: Teoria da Complexidade, Cultura de Paz, Educação para a Paz.

Education for Peace: a walk in thought complex through five integrated pedagogies and complementary

\begin{abstract}
This article presents the key elements of the thesis entitled "Culture of Peace and Education for Peace: views from the theory of Edgar Morin Complexity", defended at the Post-Graduate Education - MA, PhD, of the State University of Ponta Grossa, Paraná. The thesis, theoretical and reflective character, whose object of study Education for Peace in the light of complex thinking, suggests that the processes related to school violence and cohabitation, gain greater sense if thought the integration of five key dimensions defined as the "five pedagogies of peace": Education for Human Values, Human rights Education, Pedagogy of Conflictology, Pedagogy of eco-formation and Pedagogy of Experiences / Cohabitation. Throughout the article, we argue about such relationships. With the thesis in question is intended to advance the Education for Peace building as a field of knowledge and research in Brazil.

Keywords: Complexity Theory, Culture of Peace, Education for Peace.
\end{abstract}

\footnotetext{
Docente da Universidade Estadual de Ponta Grossa/Paraná (UEPG). Coordenador do Núcleo de Estudos e Formação de Professores em Educação para a Paz e Convivências NEP/UEPG. Doutor em Educação. E-mail: nei.uepg@gmail.com
} 


\section{Antecendentes}

Cultura de Paz e Educação para a Paz são termos que ouvimos, cada vez mais, entre os elementos necessários para a área educacional no século XXI. Esta pequena palavra, a "paz", parece tender a algum consenso relacionado aos momentos ou situações positivas, entre outras questões relacionadas a uma ideia do bem como oposição ao mal. Isto aponta para uma dimensão ligada a valores como altruísmo, respeito, tolerância, bondade, generosidade, harmonia etc. Desta noção básica, podemos pensar que tais atributos conferem à paz uma dimensão que deve, ou deveria, fazer parte do cotidiano das pessoas e também, ser alvo no ensino escolar. Estas perspectivas sobre a paz são crescentes, pois o que vemos como traço definidor da humanidade, em diferentes tempos, espaços e momentos históricos é justamente o oposto; a violência, conduzindo muitas das práticas sociais e relações entre as pessoas, grupos, países e até mesmo a relação com o planeta. Violências de múltiplas formas, das diretas às indiretas, visíveis ou invisíveis, da agressão física à miséria e a pobreza, passando pelas guerras e a falta de alimentos, em dimensões consideradas dramáticas e contraditórias para segunda década do século XXI.

Neste contexto, onde figuraria uma pretensa paz? Ela existiria concretamente? É mera utopia diante de realidades tão cruéis? A paz teria seu refúgio destinado apenas nas religiões? Mas, e a intolerância religiosa que gera tanta violência? Ainda, a paz nasceria no coração das boas pessoas? Isso é possível? Vemos que a paz parece apenas uma ideia distante e utópica, sem sentido para a realidade humana. Estaríamos destinados, portanto, a uma cultura de violência, das fatalidades, das guerras entre países, pessoas, das violências guardadas em nossas vidas como seres humanos, sociais e históricos?

Estas questões foram algumas, entre tantas, que nos provocaram ao longo dos últimos anos, como ser humano e como educador, especialmente na formação de professores, ao perceber a escalada da violência nas instituições educacionais, nos projetos sociais, nas práticas cotidianas. Com estes questionamentos, realizamos projetos profissionais dentro desta área chamada de Cultura de Paz, em nossa instituição, a Universidade Estadual de Ponta Grossa, Paraná (UEPG). Iniciamos com um projeto de pesquisa intitulado "Configurando elementos teóricos e práticos da Educação para a Paz" (2004-2006) que buscou pesquisas e práticas pedagógicas referentes à prevenção de violências, educação em valores humanos, mediação de conflitos e demais ações educacionais que poderiam ser classificadas como pertencentes ao espectro de uma Cultura de Paz na escola. Os dados do projeto de pesquisa nos remeteram ao universo 
dos estudos da Cultura de Paz como paradigma do século XXI e encontramos as primeiras referências sobre a Educação para a Paz como sua vertente pedagógica.

Ao término do projeto, com inúmeras questões encontradas, tanto em projetos como em teoria sobre a Educação para a Paz, decidimos dar visibilidade a estas, propondo o projeto de extensão "Núcleo de Estudos e Formação de Professores em Educação para a Paz e Convivências" (NEP) em funcionamento desde 2008, com a intenção de construir elementos pedagógicos da Educação para a Paz junto aos professores da educação básica, buscando as pontes entre a teoria e as questões do cotidiano educacional. A metodologia do NEP/UEPG foi construída em duas perspectivas: grupos de estudos, com número menor de professores, aprofundando as questões da Educação para a Paz e, outra dimensão, na formação de professores por meio de cursos, oficinas pedagógicas e palestras, voltadas para a intervenção em projetos escolares cotidianos. Atualmente as ações do NEP/UEPG são reconhecidas em alguns municípios da região de abrangência da Universidade Estadual de Ponta Grossa, fazendo parte das políticas públicas de educação, como na formação e certificação de professores em alternativas para a prevenção das violências e qualificação das convivências escolares.

\section{Caminhos trilhados}

A partir destes anos de movimento do NEP/UEPG, marcados por experiências ricas e de muitas reflexões, uma questão ainda insistia: a fragilidade da ideia de Educação para a Paz, que mesmo com sua repercussão positiva nos projetos escolares, ainda não conseguia a sustentabilidade destes, devido à falta de uma reflexão teórica adequada à realidade educacional brasileira, visto que os principais teóricos da área são de outros países. Junto a isso, outra questão que notamos foi o receio de parte meio acadêmico, que desconsidera os estudos sobre a Cultura de Paz e a Educação para a $\mathrm{Paz}$, tratando-os como temas utópicos ou inespecíficos, numa expressão, como algo "menor" e que não tem espaço no ensino superior e na pesquisa. Tal desconfiança, porém, traz argumentos válidos no sentido de pensar um objeto mais definido, provocando discussões para que se explicite se a Cultura de Paz e a Educação para a Paz seriam temas, disciplinas, conteúdos ou somente um conjunto de práticas educativas e ainda, se podem constituir-se em campo específico.

Assim, questiona-se sobre uma fundamentação teórica para a Cultura de Paz e a Educação para a Paz, alegando a falta de profundidade ou de práticas mais ingênuas do que críticas nas escolas. No Brasil, temos cerca de uma década de práticas escolares e educacionais tematizando a Paz, bem como estudos e publicações acadêmicas que 
procuram dar visibilidade ao tema. De forma geral isto é muito positivo para difundir experiências, porém, por outro lado, cabe um exame crítico destas práticas e a necessidade de procurar nelas, alguns conceitos básicos. Assim, vimos que tal demanda, seja em teoria ou em prática pedagógica, precisa ser reconhecida pela educação superior, tanto no ensino, como na pesquisa e extensão. Para isso, a pesquisa de base, sobre o campo emergente é o caminho fundamental.

Portanto, considerando as experiências e reflexões acumuladas ao longo da trajetória do NEP/UEPG e a necessidade de discussão de elementos mais concretos para elaborar uma sistematização de conhecimentos sobre a Educação para a Paz, desenvolvemos uma pesquisa de doutorado (2012-2015), no Programa de Pós-Graduação em Educação em Educação da UEPG, sobre Cultura de Paz e a Educação para a Paz na perspectiva do pensamento complexo de Edgar Morin, que objetiva fundamentar a discussão da área da Educação para a Paz. Ao configurar a pesquisa, fizemos uma distinção básica e fundamental, que permeou todo o desenvolvimento do estudo. A Cultura de Paz e a Educação para a Paz são ideias/conceitos diferentes, embora complementares em essência. Como Cultura de Paz entende-se o grande campo de atividades humanas que levem em conta um mundo melhor, mais humano, mais feliz e sustentável. Assim, a Cultura de Paz cabe e vale para todos os seres humanos. Ao mesmo tempo, vê-se que é uma ideia inespecífica, se a Cultura de Paz é feita de todas as coisas positivas, alguém poderia ser contrário a ela? Tanto sabemos que sim, que a as diferentes formas de violência constituem-se num dos maiores problemas da humanidade em geral, e também dos países, cidades, comunidades, escolas etc. Neste quadro, a Educação para a Paz surge como a vertente educacional na Cultura de Paz, um campo construído e pensado com ações pedagógicas voltadas ao esclarecimento sobre a cultura das violências em seu processo de mudanças para uma Cultura de Paz. Assim, a Educação para a Paz é um campo de ensino, que pode e precisa ser estudado, devidamente articulado com a Cultura de Paz, para que sejam definidos seus aspectos básicos devidamente claros e dotados de aplicabilidade no cotidiano educacional.

Tais perspectivas não estão no vazio, pois, existe objetivamente, uma teoria fundamentada da Educação para a Paz, vinda de quase cinco décadas na Europa e que tomou contornos metodológicos na Espanha nos últimos trinta anos, tendo como alguns de seus expoentes Jares (2002), Rayo (2004) e Serrano (2002). Ao mesmo tempo, não há, no Brasil, aprofundamento na discussão da teoria da Educação para a Paz com princípios educacionais mais amplos e atentos à realidade de nosso país. Vemos que a discussão mais ampla tem um viés eurocêntrico, com formas de convivências e violências que tem aproximações e diferenças com a realidade da América Latina e do 
Brasil. Considerando isso, vemos que as práticas educacionais referentes ao tema ainda são difusas e transformam-se em ações pedagógicas sem força geradora de mudanças na forma de pensar os problemas humanos de nossa geração, repletos de violências, além de não reconhecer da importância das convivências escolares para a busca de mudanças neste cenário. É muito comum que os projetos de paz estejam associados ao desenho de "pombinhas brancas", a raras músicas com o tema e com um grande "abraços na escola". Claro que estas práticas têm seu espaço, mas precisamos de mais, de leituras críticas sobre os valores humanos e os valores de convivência, além de uma visão crítica sobre os direitos humanos. Junto a isso, precisamos igualmente, entender os processos de conflito entre pessoas, grupos e na sociedade, além de seus processos de mediação. Precisamos estender também o olhar sobre o meio ambiente, como nossa casa maior, onde as dimensões objetivas e subjetivas de nossa vida precisam ser valorizadas, no encontro entre mundo do trabalho, mundo da vida e a transcendência, constituindo o que chamamos de ecoformação.

Nesse sentido vemos que, embora a Educação para a Paz possua um corpo de conhecimentos já desenvolvido, é importante observar os demais saberes a ela associados, para rediscutir e redimensionar as dimensões teóricas ampliadas para aproximá -las de realidades presentes ao contexto escolar brasileiro, incorporados às dimensões culturais, econômicas, sociais e educacionais que compõe a diversidade em nosso país. Tais aspectos são necessários, pois neles encontram-se as raízes dos diversos problemas geradores de violências que se configuram nas escolas, bem como as convivências decorrentes da forma de ser, de conhecer e de viver. Uma dimensão importante é entender que Educação para a Paz implica pensar numa discussão pedagógica ampla, que envolve os diferentes atores e processos causadores sociais amplos, sejam estruturais ou pessoais, que acabam interferindo em questões básicas às vivências/convivências humanas, seja na violência pessoal ou na pobreza e injustiças sociais que também impedem a vida plena cidadã. Nesse sentido, Jares (2007, p. 44-45) diz que:

[...] concebemos a EP como um processo educativo, contínuo e permanente, fundamentado nos dois conceitos fundadores (concepção de paz positiva e perspectiva criativa do conflito), que, pela aplicação de métodos problematizantes, pretende desenvolver um novo tipo de cultura, a cultura de paz, que ajude as pessoas a entender criticamente a realidade, desigual, violenta, complexa e conflituosa, para poder ter uma atitude e uma ação diante dela.

Explicamos que a concepção de paz positiva, colocada por Jares (2007) no conceito, remete à paz como forma de desenvolvimento humano e relacionada à 
história e sociedade, e, a perspectiva criativa do conflito como estratégias para a mediação e resolução não violenta dos mesmos. Nossa tese, pensada, à luz destas reflexões e experiências amplas, encontra o pensamento de Edgar Morin que discute o paradigma da complexidade como forma de leitura e vivência no mundo. Deste ponto de vista, cremos que nosso olhar aproxima da seguinte ideia: "Quando falamos da crise da educação, o que vem primeiro à mente são os aspectos impressionantes, em todos os sentidos do termo, da violência na escola" (MORIN, 2015, p. 57). Ao discutirmos sobre a amplitude deste termo violências, mais uma vez Morin (2015, p. 57) nos ajuda: "Nesse caso, é preciso admitir que a crise do ensino é inseparável de uma crise de cultura".

Portanto, ao pensarmos a Educação para a Paz, além dos aspectos do saber conhecer, ou seja, da discussão crítica sobre os problemas da humanidade para nos posicionarmos com mais clareza e autonomia, também acreditamos que é necessário, de maneira complementar, explicitar as outras violências, menos visíveis, mas igualmente angustiantes para os seres humanos do século XXI, que são os dilemas relacionados ao saber viver, percebidos por Morin (2015, p. 64-65) que diz:

Não devemos, não podemos isolar essa crise da educação de uma crise de civilização, da qual ela é um componente: degradação das solidariedades tradicionais (grande família, vizinhança, trabalho), perda ou degradação do supereu de pertencimento a uma nação, ausência de um supereu de pertencimento à humanidade, individualismo cuja autonomia relativa é menos responsável do que egocêntrica, generalização dos comportamentos incivis, a começar pela ausência de saudação e de cortesia, compartimentalização dos escritórios, dos serviços, das tarefas em uma mesma administração ou empresa, ausência generalizada de religações, desmoralizações ou angústias do presente e do futuro.

A partir desta complexidade, vemos que os problemas da civilização, no excesso de valorizar a objetividade, relegou a subjetividade a algo desnecessário de ser pensada ou discutida em vários níveis, entre eles a educação e a escola. Portanto, diante dos esgotamentos humanos, sociais e ambientais deste século, a vertente crítica, da "luta de classes", precisa encontrar-se, de maneira rápida com a perspectiva complementar e também crítica, mas que aponta para a "colaboração e cooperação entre classes". A objetividade perante os problemas humanos, precisa alimentar-se da subjetividade, onde a emoção passa a ser elemento central e importante para as mudanças necessárias. Assim, a perspectiva da complexidade 
aponta para o ser humano integrado nas diferentes dimensões de sua existência, sem perder-se no relativismo, mas buscando as conexões entre os elementos que compõe sua vida. Como diz Morin (2015), a busca por estas mudanças seria bem mais que uma reforma ou uma revolução, mas seria uma metamorfose, na forma de pensar a humanidade.

Baseado nas questões evidenciadas, desenvolvemos a tese, balizada na seguinte questão central: será a Educação para a Paz, uma área de conhecimento catalisadora do entendimento da Cultura de Paz, através da estruturação pedagógica das questões relativas aos valores humanos, direitos humanos, conflitologia, ecoformação e vivências/convivências escolares, dentro do paradigma da complexidade?

Neste ponto, consideramos a advertência cuidadosa de Minayo (2001, p. 17): "nada pode ser intelectualmente um problema se não tiver sido, em primeiro lugar, um problema da vida prática”. Nosso problema prático são as violências e convivências nas escolas, pensadas sob suas múltiplas formas, que não apenas as "brigas na saída", mas em toda sua dimensão, desde as relações de convívio de clima escolar, dos conflitos, que levam aos problemas maiores, as violências em múltiplas formas. Porém, o que vemos em realidade, baseado nas experiências profissionais colhidas durante o trabalho no NEP/UEPG, pelos estudos e práticas, é que vários caminhos tentam contribuir com esta ideia da Cultura de Paz nas escolas, favorecendo as relações humanas, convivências e prevenção das violências escolares, ainda de maneira fragmentada e desarticulada a princípios educacionais claros, fora de sintonia com os projetos pedagógicos institucionais e ainda mais desconectados da complexidade dos problemas humanos de nosso tempo.

Uma parte destes caminhos são os estudos de Jares (2002) Rayo (2004) e Serrano (2002) que serão aqui descritos brevemente no quadro, que explicitam as questões fundamentais destes três teóricos relevantes aos estudos da Educação para a Paz. Este quadro, sintetiza a perspectiva dos autores sob algumas dimensões como: "questões gerais"; "bases na Educação para a Paz"; "temas de aprofundamento" e " elementos pedagógicos". 


\section{Quadro - Aspectos centrais da Educação para a Paz}

\begin{tabular}{|c|c|c|c|}
\hline Aspectos & Serrano & Rayo & Jares \\
\hline $\begin{array}{l}\text { Questões } \\
\text { Gerais }\end{array}$ & $\begin{array}{l}\text { Tolerância como va- } \\
\text { lor fundamental; Paz, } \\
\text { direitos humanos e } \\
\text { democracia; socie- } \\
\text { dade pluralista; "paz } \\
\text { passiva X paz ativa"; } \\
\text { transversalidade. }\end{array}$ & $\begin{array}{l}\text { Paz e desenvolvimen- } \\
\text { to humano; direitos } \\
\text { humanos; natureza e } \\
\text { meio ambiente; ên- } \\
\text { fase transdisciplinar; } \\
\text { democracia e enten- } \\
\text { dimento internacio- } \\
\text { nal; transversalidade. }\end{array}$ & $\begin{array}{l}\text { Importância da "pesqui- } \\
\text { sa pela paz"; explicita- } \\
\text { ção de Johann Galtung } \\
\text { como teórico funda- } \\
\text { mental dos estudos da } \\
\text { paz; educar numa pers- } \\
\text { pectiva crítica e criativa; } \\
\text { transversalidade. }\end{array}$ \\
\hline $\begin{array}{l}\text { Bases na Edu- } \\
\text { cação para a } \\
\text { Paz }\end{array}$ & $\begin{array}{l}\text { Desenvolver pessoas; } \\
\text { potencializar relações } \\
\text { com o meio; fomentar } \\
\text { diálogo e espírito crí- } \\
\text { tico; favorecer o com- } \\
\text { promisso. }\end{array}$ & $\begin{array}{l}\text { Paz como um "direi- } \\
\text { to humano"; valori- } \\
\text { zação de documen- } \\
\text { tos internacionais } \\
\text { (ONU, UNESCO, } \\
\text { etc.); considerar as } \\
\text { relações com a ciên- } \\
\text { cia, cultura, comuni- } \\
\text { cação, exclusão, dis- } \\
\text { criminação, conflitos } \\
\text { étnicos, pobreza, } \\
\text { justiça, desemprego, } \\
\text { migrações. }\end{array}$ & $\begin{array}{l}\text { Didática do conflito } \\
\text { (relações entre violên- } \\
\text { cia-paz -conflitos); mo- } \\
\text { delos de educação para a } \\
\text { paz (técnico-positivista, } \\
\text { hermenêutico-interpre- } \\
\text { tativo e sócio crítico). } \\
\text { Ênfase no modelo sócio } \\
\text { crítico. }\end{array}$ \\
\hline $\begin{array}{l}\text { Temas de } \\
\text { aprofunda- } \\
\text { mento }\end{array}$ & $\begin{array}{l}\text { Educação para a Paz } \\
\text { no currículo esco- } \\
\text { lar; educação moral } \\
\text { e cívica (contexto da } \\
\text { Espanha); educação } \\
\text { em valores humanos, } \\
\text { educação para a con- } \\
\text { vivência, solidarieda- } \\
\text { de; }\end{array}$ & $\begin{array}{l}\text { D es a r m a me nto; } \\
\text { compromisso mo- } \\
\text { ral e cívico para um } \\
\text { mundo melhor; sen- } \\
\text { tido global para edu- } \\
\text { car para a paz; cultu- } \\
\text { ra, natureza e meio } \\
\text { ambiente; valoriza- } \\
\text { ção da convivência; } \\
\text { valores implícitos aos } \\
\text { problemas humanos }\end{array}$ & $\begin{array}{l}\text { Resolução não violenta } \\
\text { dos conflitos; explicitar } \\
\text { os conflitos de valores; } \\
\text { buscar elementos críti- } \\
\text { cos à sociedade violenta } \\
\text { e desigual; história da } \\
\text { educação para a paz. }\end{array}$ \\
\hline
\end{tabular}




\begin{tabular}{|c|c|c|c|}
\hline $\begin{array}{l}\text { Elementos } \\
\text { Pedagógicos }\end{array}$ & $\begin{array}{l}\text { Esclarecimento sobre } \\
\text { valores humanos; dis- } \\
\text { cussão sobre dilemas } \\
\text { morais; resolução de } \\
\text { conflitos; habilidades } \\
\text { sociais; estudo de ca- } \\
\text { sos; grupos de discus- } \\
\text { são; jogos de simula- } \\
\text { ção, diálogo a partir } \\
\text { de notícias cotidianas; } \\
\text { músicas; jogos coope- } \\
\text { rativos; apresentação } \\
\text { de problemas para } \\
\text { solução coletiva e } \\
\text { criativa. }\end{array}$ & $\begin{array}{l}\text { Resolução não-vio- } \\
\text { lenta dos conflitos; } \\
\text { educação mundia- } \\
\text { lista (compreensão } \\
\text { internacional); edu- } \\
\text { cação intercultural; } \\
\text { educação para o de- } \\
\text { sarmamento; educa- } \\
\text { ção para ao desenvol- } \\
\text { vimento. Foco em: } \\
\text { educação cognitiva } \\
\text {-afetiva (compreen- } \\
\text { são e sensibilização), } \\
\text { educação sociopo- } \\
\text { lítica (paz e direitos } \\
\text { humanos) e educa- } \\
\text { ção ambiental (fauna } \\
\text { e flora, demografia, } \\
\text { saúde, consumo - } \\
\text { sustentabilidade). }\end{array}$ & $\begin{array}{l}\text { Educação para a com- } \\
\text { preensão internacional; } \\
\text { educação para os di- } \\
\text { reitos humanos; edu- } \\
\text { cação mundialista e } \\
\text { multicultural; educação } \\
\text { intercultural; educação } \\
\text { para o desarmamento; } \\
\text { educação para o desen- } \\
\text { volvimento; educação } \\
\text { para o conflito e a de- } \\
\text { sobediência, através de } \\
\text { técnicas cooperativas; } \\
\text { enfoque socioafetivo; } \\
\text { assembleias, dinâmicas } \\
\text { lúdicas (jogos coope- } \\
\text { rativos, de simulação, } \\
\text { de papéis); ênfase nas } \\
\text { questões conceituais, } \\
\text { procedimentais e sociais } \\
\text { de cada atividade. }\end{array}$ \\
\hline
\end{tabular}

\section{Quadro - Baseado em Serrano (2002), Rayo (2004) e Jares (2002)}

Em relação ao quadro, quanto ao item "questões gerais" podemos dizer que, seguramente, que os temas fortemente relacionados à Educação para a Paz, são suas relações com os valores humanos, direitos humanos, democracia e desenvolvimento. Nisso, os três pesquisadores concordam que a Educação para a Paz tem uma perspectiva complexa. Da mesma forma que o entendimento de transversalidade, tanto do sentido do entendimento quanto da prática pedagógica, a Educação para a Paz pode transpassar áreas do conhecimento, o que reforça seu caráter transdisciplinar, que busca uma abrangência na ação.

A noção de transdisciplinaridade será importante neste desdobramento, fundamentalmente no sentido proposto por Nicolescu (2000) como as quatro flechas do conhecimento: disciplinaridade, multidisciplinaridade, interdisciplinaridade e transdisciplinaridade. Julgamos esta observação necessária, uma vez que a complexidade não aceita a ciência em fragmentos como possibilidade de mudança efetiva na humanidade, embora a valorize como caminho. Por isso os prefixos multi, inter e trans, 
representam avanços na articulação dos conhecimentos disciplinares, cada um com um grau de possibilidade. A esse respeito, Morin (2013, p.193) diz:

Um novo sistema de educação, fundado da religação, e por isso, radicalmente diferente do atual, deveria substituí-lo. Esse sistema permitiria favorecer a capacidade da mente para pensar os problemas individuais e coletivos em sua complexidade. Ele sensibilizaria para a ambiguidade e ambivalências, e ensinaria a associar os termos antagônicos para apreender uma complexidade.

Neste aspecto consideramos que, mesmo em suas aproximações, como percebido no quadro, especialmente nos itens "bases na educação para a paz" e "temas de aprofundamento", os autores ainda seguem um caminhos mais próximo ao "inter ou multi" disciplinaridade, uma vez que os temas são correlacionados, mas não integrados em seu sentido mais profundo. Isso será refletido no item "elementos pedagógicos", onde surgem possíveis "conteúdos" da Educação para a Paz, especialmente entre Rayo (2004) e Jares (2002). Ao aprofundar em possíveis "conteúdos de ensino da educação para a paz", os pesquisadores, ao mesmo tempo em que contribuem significativamente com a área, acabam por dotá-la de uma especificidade que corre o risco de fragmentação do conhecimento.

Um exemplo disso seria o tema "desarmamento", que pode ser entendido como função da polícia ou exército, logo, sendo trabalhado isoladamente de uma proposta ampla de Educação para a Paz, num paradigma integrador da Cultura de Paz. Assim se assemelhariam os "projetos de valores nas escolas", "projetos de meio ambiente", "projetos de interculturalidade e multiculturalidade", que muitas vezes são tratados em cima de perspectivas clássicas da educação, como aproveitar datas (no Brasil) como o "dia do índio", "dia da consciência negra" e "dia da árvore" de maneira que reproduza os mesmos estereótipos e os mesmos modos de pensar o mundo, sempre dividido e nunca cooperativo. De alguma forma, todos estes projetos apontam para certa sensibilização e ações que contribuem para uma Cultura de Paz, mas, será que garantem que exista uma conscientização e noção de Educação para a Paz, como campo de crítica aos problemas de forma ampla, relacional e integrada? Ou ainda correremos o risco de especialistas em "conteúdos de paz", cada um com sua "área de conhecimento", na reprodução dos mesmos argumentos, sem ligar ao contexto maior, com elaboração crítica e voltado a mudanças nas formas de viver e conviver?

Acreditamos a noção de complexidade é importante na definição e nos olhares para o que efetivamente será ensinado com Educação para a Paz. No caso da pro- 
posição de elementos pedagógicos, a noção de transdisciplinaridade é tomada como condição de ligação/religação das áreas, num mesmo movimento e intencionalidade, e não como "partes". Esta perspectiva complexa, multidisciplinar e muito próxima ao que propomos como paradigma da Cultura de Paz é evidenciada por Suanno (2015, p.109):

O olhar transdisciplinar é uma nova maneira de pensar, de sentir, de perceber a realidade e interagir que se projeta na vida pessoal, profissional e social, por isso que essa religação ecológica entre indivíduo, a sociedade e a natureza têm suas consequências em uma cidadania planetária constituída por seres humanos dotados de direitos e liberdades. Práticas transdisciplinares baseadas no respeito, na convivência, na conservação dos meios naturais, na melhoria das condições de vida, no consumo consciente e na produção que não menospreze os direitos humanos nem o bem-estar psicossocial da pessoa fazem-se fundamentais nas atuais realidades social, institucional e educacional.

Considerando estas questões, que aprofundamos ao longo da pesquisa, a ponte com os "sete saberes da educação" de Morin (2011), é imprescindível. Vemos os saberes: as cegueiras do conhecimento; o conhecimento pertinente; ensinar a condição humana; ensinar a identidade terrena; enfrentar as incertezas; ensinar a compreensão e a ética do gênero humano, que constituirão os fundamentos do que chamamos de as "Cinco Pedagogias da Paz".

Tal proposta surge do desdobramento das questões da tese, unidas ao pensamento pedagógico acumulado em experiências e vivências com ações de Educação para a Paz nos últimos anos, percebendo suas possibilidades como temas geradores de ações positivas. Ressaltamos que as pedagogias da paz, propostas de forma integrada, tem sentido especialmente se pensadas à luz do pensamento complexo de Edgar Morin, tanto em seus aspectos gerais, como na discussão sobre a Cultura de Paz e a Educação para a Paz. Apontamos a seguir a noção básica das cinco pedagogias, que trataremos com aprofundamento no próximo capítulo.

Destacamos como o primeiro eixo, ou a primeira pedagogia, a Pedagogia dos Valores Humanos, evidenciando que tem um aspecto chave entre os pesquisadores da Educação para a Paz. Os valores humanos estão na base do comportamento humano, em todos os pensamentos e ações humanas, além de criar/recriar a sociedade. Podemos dizer que os valores humanos compõem a própria história e o desenvolvimento da humanidade, sempre no fluxo que aponta valores que podem ser próximos, con- 
traditórios ou em construção. Portanto, na busca de equilíbrio entre valores seculares e valores cotidianos, criados e recriados, em mutação nas diferentes culturas e povos, em grupos comunitários diversos, que encontraremos as bases para a construção dos direitos humanos, que preservem este conjunto de valores. Assim, de forma interligada entende-se a Pedagogia dos Direitos Humanos, não apenas como a informação e ensino da "Declaração dos Direitos Humanos Universais", mas como tudo aquilo que se apresenta como "direito à paz" (RAYO, 2004) na perspectiva do que historicamente foi agregado no desenvolvimento de práticas, convenções e leis destinadas à promoção e preservação da vida em todos os sentidos, na dimensão individual, social e planetária. Portanto não basta informar sobre Direitos Humanos, se as condições para que sejam efetivamente postos em prática contra as injustiças e desigualdades da comunidade global.

Considerando as profundas diferenças históricas, culturais, sociais, econômicas entre tantos povos, países, grupos, é natural que muitas situações presentes em relação aos valores humanos e direitos humanos sejam palco de debates e divergências. Tais perspectivas opostas, chamadas de conflitos, muitas vezes levam a múltiplas formas de violência. Assim, estabelecemos o terceiro eixo, a Pedagogia da Conflitologia como espaço destinado a encontrar equilíbrio nas inúmeras diferenças humanas. Questões como resolução de conflitos, mediação, práticas restaurativas, crescem de forma muito consistente na sociedade das últimas décadas, como alternativa às "vias de fato", quando intolerância supera o respeito à diversidade. A conflitologia, também como campo de conhecimento, nessa relação integrada aos valores e direitos gera a sensibilização ao outro ser humano e às outras culturas, abrindo novas formas de relacionamento, humanizando pensamentos, ações e reações. Valores humanos, direitos humanos e conflitologia constituem-se em pedagogias próprias, mas que, articuladas na perspectiva da complexidade promovem uma mudança de sentido do ser humano no mundo.

Ao falar de "ser humano no mundo", pensamos também em cidadania planetária, como aponta Morin (2011) e naquilo que Rayo (2004) nominou, porém sem desenvolver a ideia, que é "ecopacificar" a sociedade. Deste conjunto de ações do ser humano no mundo, sociedade e planeta, que também precisa ser preservado, posto que, está em esgotamento em seus recursos naturais, enfrentando inúmeras catástrofes ambientais recentes, é que integra-se à Educação para a Paz um quarto eixo, a Pedagogia da Ecoformação, entendida como a união entre "educação ambiental junto com uma educação para ao desenvolvimento sustentável, ou a educação para os direitos humanos e a paz. Isso tudo passa pela educação para a solidariedade, do compromisso com toda a terra e com os seus habitantes" (NAVARRA, 2008, p.251). 
Portanto, a ecoformação buscará e relação ser humano/ser planetário, não somente como um conjunto de práticas ecologicamente sustentáveis do meio ambiente, mas como o redimensionamento da ideia de preservar e sustentar a vida da forma mais plena e realizada no sentido da relação com todas as formas de existência no planeta. Cuidar da água, nesse limite é buscar a paz, no sentido que o descuido com ela levará à morte. Tratar as árvores com humanidade significa prevenir a degradação do meio ambiente, que adiante poderá causar desmoronamentos e mortes, além de prejuízo às pessoas em zonas de risco. No limite, a ecoformação aprofunda na relação homem e natureza naquilo que mais existe de sensibilidade, o que podemos aproximar reflexivamente da espiritualidade, não como religião, mas como transcendência. Como diz claramente Suanno (2014, p.175), a ecoformação se constrói com o desenvolvimento de "uma educação ambiental, também atenta aos direitos humanos e à paz".

Os debates sobre a preservação da vida e do planeta, também estão sob a tensão de divergências de poder geográfico e econômico (conflitologia), envolvem legislação e busca conjunta pela diminuição dos impactos (direitos humanos), além da construção de novos valores, voltados à espiritualidade e à sustentabilidade (valores humanos). Da articulação destes quatro eixos: Pedagogia dos Valores Humanos, Pedagogia dos Direitos Humanos, Pedagogia da Conflitologia e Pedagogia da Ecoformação, acreditamos que, na perspectiva da complexidade, conseguimos intercambiar os elementos propostos pela Educação para a Paz com os saberes da educação para ao século XXI. Porém, abre-se outra necessidade, como fazer para que isso ocorra na prática educacional? Aqui, a afirmação de Rabbani (2003, p.65) é precisa: “A transmissão de conhecimento científico, já sabemos, não promove a paz. Apenas informar sobre a paz, as distintas formas de violência, a história da guerra e a importância do desarme ou de uma conduta eticamente correta, tampouco conleva à paz". Isso significa dizer que precisamos alterar as formas de viver e conviver nas escolas, nas relações, para verdadeiramente pensarmos em um paradigma de Cultura de Paz. Esta reflexão nos leva ao quinto eixo, naturalmente decorrentes e articulados a partir dos outros quatro: a Pedagogia das Vivências/Convivências. Esta pedagogia da prática pedagógica da Educação para a Paz sugere recursos educacionais que estarão em estreita sintonia com os pressupostos das demais pedagogias da paz e que tem na ludicidade e na corporeidade algumas de suas bases. Nas palavras de Moraes (2010, p.54): "Cognição e vida não estão separadas, e o conhecimento acontece no cotidiano da vida, no viver/conviver" e ainda "Aprendizagem surge a partir do acoplamento estrutural do sujeito com o mundo. É um processo que se estabelece no viver/conviver [...]" (2010, p.54)

Para perceber a importância desta ligação entre os saberes das cinco áreas 
apontadas como componentes da Educação para a Paz, apresentamos uma figura que evidencia a relação. Ao centro, a imagem em forma de estrela, apontando e inserindo-se com cada ponta em uma das chamadas "pedagogias da paz". Esta representação evita a necessidade de setas que ligam um elemento ao outro, mas significa todos os elementos fazendo parte do todo, da Educação para a Paz. A estrela, neste caso, é interpretada como luz que ilumina os caminhos integrados, ou como o núcleo onde as cinco pedagogias podem circular entre elas, mesmo considerando suas especificidades.

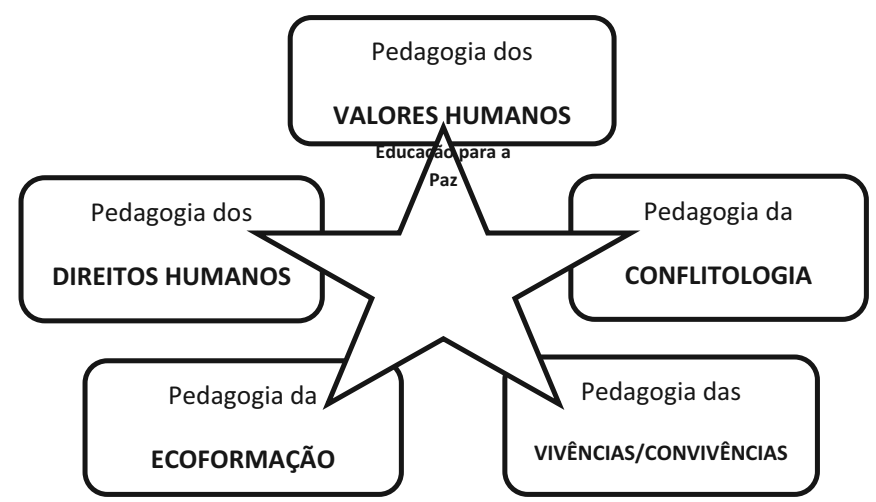

Fig. - As "Cinco Pedagogias da Paz"

Fonte: Salles Filho (2016)

\section{Alongamentos reflexivos}

Propor um olhar complexo para a Educação para a Paz, em nosso estudo, buscou encontrar a relação entre algumas áreas que alimentam as questões sobre convivências e violências, que possuem sua especificidade, mas que, ao mesmo tempo podem ser redimensionadas, considerando suas interfaces com dimensões relacionadas aos saberes da educação na complexidade e da Cultura de Paz. Portanto, caminhamos na construção da Educação para a Paz, nas tensões e complementos entre saberes e conhecimentos que contribuam no processo educacional que busca uma Cultura de Paz.

Neste sentido, a discussão sobre "as cinco pedagogias da paz", estruturadas a partir das questões relevantes que decorrem do paradigma da Cultura de Paz e das discussões da Educação para a Paz, aponta para a dupla questão transversalidade- 
transdisciplinaridade como abordagem que, de forma coerente e sistematizada, encontra elementos entrecruzados na constituição de: Pedagogia dos Valores Humanos, Pedagogia dos Direitos Humanos, Pedagogia da Conflitologia, Pedagogia da Ecoformação e Pedagogia das Vivências/Convivências, buscando sua especificidade e complementaridade. Deste conjunto de informações, abrem-se possibilidades importantes na análise de projetos pedagógicos e discussões teóricas referentes à Educação para a Paz como campo de conhecimento e pesquisa.

Como observação final e relevante às questões levantadas, acreditamos que mesmo que esta tese aponte para questões teóricas, como suporte às discussões pedagógicas, é importante reconhecer o avanço, para o campo integrado da Cultura de Paz e Educação para a Paz, do seu reconhecimento no Plano Nacional de Educação (PNE 2014-2024) no Brasil, quando explicita em sua Meta 7, item número 7.23, a seguinte redação:

Garantir políticas de combate à violência na escola, inclusive pelo desenvolvimento de ações destinadas à capacitação de educadores para detecção dos sinais de suas causas, como a violência doméstica e sexual, favorecendo a adoção das providências adequadas que promovam a construção da cultura de paz e um ambiente escolar dotado de segurança para a comunidade (BRASIL, 2014, p. 65).

Mesmo que seja apenas este artigo no PNE, em meio a tantas outras demandas, vemos como o primeiro aspecto formalizado na busca de explicitar, ampliar a discussão e pensar ações pedagógicas sérias dentro da questão da Cultura de Paz. $\mathrm{O}$ artigo, que ainda é inespecífico, pois traz muitas questões sobre a ótica abrangente da Cultura de Paz, certamente encontrará eco nas ações já realizadas nas escolas do país. A partir deste componente, as muitas experiências da Educação para a Paz nos últimos anos, em diferentes cidades, estados e regiões do país, vão sendo introduzidas nos planos municipais e estaduais de educação e serão, certamente, ampliados ao longo deste ciclo do PNE. Por isso, também acreditamos que pesquisar este objeto, em suas relações ampliadas, é fundamental para os próximos desdobramentos da educação e da Educação para a Paz na educação brasileira. Um campo que já tem inúmeras experiências e que, ao mesmo tempo, requer sistematiza-las como forma de difundir suas bases de conhecimento para um maior número de profissionais e instituições educacionais. 


\section{Referências}

BRASIL. Plano Nacional de Educação 2014-2024: Lei no 13.005, de 25 de junho de 2014, que aprova o Plano Nacional de Educação (PNE) e dá outras providências. Brasília: Câmara dos Deputados, Edições Câmara, 2014. 86 p.

JARES, X.R.. Educação para a paz: sua teoria e sua prática. 2. ed. rev. Tradução de Fátima Murad, Porto Alegre Artmed: 2002. 271 p.

Educar para a paz em tempos difíceis. Tradução de Elizabete de Moraes Santana. São Paulo: Palas Athena, 2007. 193 p.

MINAYO, M. C. Pesquisa social: teoria, método e criatividade. Petrópolis: Vozes, 2001. $80 \mathrm{p}$.

MORAES, M.C. Ambientes de aprendizagem como expressão de convivência e transformação. In: MORAES, M.C.; BATALLOSO NAVAS, J.M. (orgs.) Complexidade e transdisciplinaridade em educação: teoria e prática docente. Rio de Janeiro : Wak Editora, 2010. p. 21-62.

MORIN, E. Os sete saberes necessários à educação do futuro. 2 ed. rev. Tradução de Catarina Eleonora F. da Silva e Jeanne Sawaya; revisão técnica de Edgard Assis de Carvalho. São Paulo: Cortez ; Brasília, DF: Unesco, 2011. 102 p.

. A via para o futuro da humanidade. Tradução de Edgard Assis de Carvalho e Mariza Perassi Bosco. Rio de Janeiro: Bertrand Brasil, 2013. 392 p.

. Ensinar a viver: manifesto para mudar a educação. Tradução de Edgard Assis de Carvalho e Mariza Pessari Bosco. Porto Alegre: Sulina, 2015. 183 p.

NAVARRA, J.M. Ecoformação: além da educação ambiental. In: LA TORRE, S. (org). Transdisciplinaridade e Ecoformação: um novo olhar sobre a educação. São Paulo: TRIOM, 2008. p. 235 - 260.

NICOLESCU, B. Um novo tipo de conhecimento: transdisciplinaridade. In: NICOLESCU et al. Educação e transdisciplinaridade. Brasília: UNESCO, 2000. p 13-19. 
RABBANI, M. J. Educação para a Paz: desenvolvimento histórico, objetivos e metodologia. In: MILANI, F. (org.) Cultura de Paz: estratégias, mapas e bússolas. Salvador: INPAZ, 2003. p. 63-95.

RAYO, J. T. Educação em direitos humanos: rumo a uma perspectiva global. Tradução de Jussara Haubert Rodrigues. Porto Alegre: Artmed, 2004. p. 247.

SALLES FILHO, N. A. Cultura de Paz e Educação para a Paz: olhares a partir da Teoria da Complexidade de Edgar Morin. Doutorado em Educação - Linha de Pesquisa: Ensino e Aprendizagem. Universidade Estadual de Ponta Grossa.

SERRANO, G. P. Educação em valores: como educar para a democracia. Tradução de Fátima Murad. Porto Alegre: Artmed, 2002. 282 p.

SUANNO, J.H. Ecoformação, transdisciplinaridade e criatividade: a escola e a formação do cidadão no século XXI . In: MORAES, M.C. ; SUANNO, J.H. (orgs.) O pensar complexo na educação: sustentabilidade, transdisciplinaridade e criatividade. Rio de Janeiro: Wak, 2014. p. 171-181.

- Transdisciplinaridade, criatividade e o terceiro incluído na formação de professores. In: BEHRENS, M.A ; ENS, R.T. (orgs.) Complexidade e transdisciplinaridade: novas perspectivas teóricas e práticas na formação de professores. Curitiba: Appris, 2015. p. 107-122.

SUANNO, M. V. R. Educar em prol da Macrotransição: emerge uma didática complexa e transdisciplinar. In: BEHRENS, M.A.; ENS, R.T. Complexidade e transdisciplinaridade: novas perspectivas teóricas e práticas para a formação de professores. Curitiba: Appris, 2015. p. 199-214.

Recebido em: 09 abril 2016

Aceito em: 19 abril 2016 